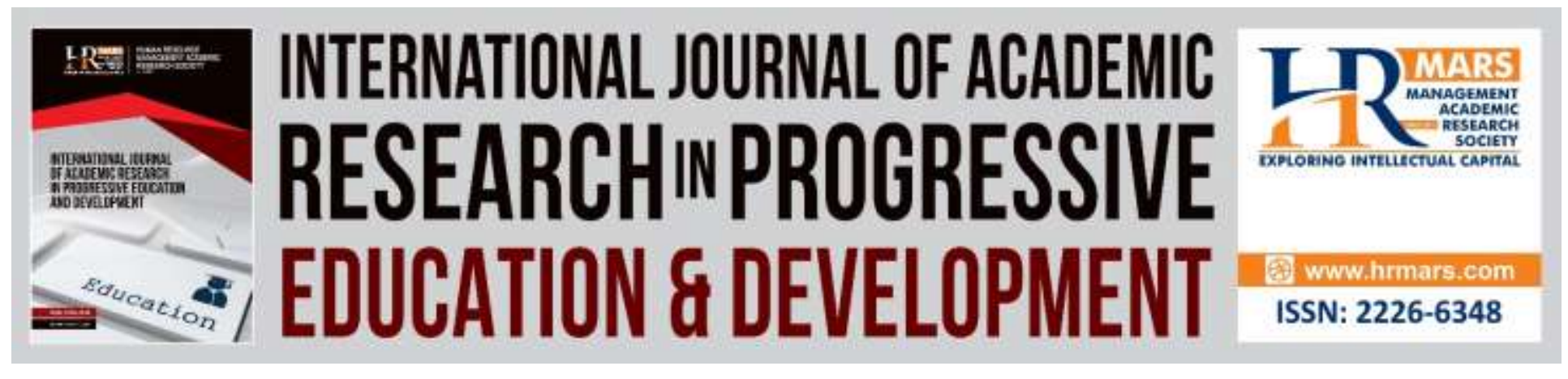

\title{
Augmented Reality in Teaching and Learning English Reading: Realities, Possibilities, and Limitations
}

\author{
Mohd Hafizuddin Mohamed Jamrus, Abu Bakar Razali
}

To Link this Article: http://dx.doi.org/10.6007/IJARPED/v8-i4/6696

DOI:10.6007/IJARPED/v8-i4/6696

Received: 10 October 2019, Revised: 24 October 2019, Accepted: 10 November 2019

Published Online: 29 November 2019

In-Text Citation: (Jamrus, \& Razali, 2019)

To Cite this Article: Jamrus, M. H. M., \& Razali, A. B. (2019). Augmented Reality in Teaching and Learning English Reading: Realities, Possibilities, and Limitations. International Journal of Academic Research in Progressive Education and Development, 8(4), 724-737.

Copyright: (C) 2019 The Author(s)

Published by Human Resource Management Academic Research Society (www.hrmars.com)

This article is published under the Creative Commons Attribution (CC BY 4.0) license. Anyone may reproduce, distribute, translate and create derivative works of this article (for both commercial and non-commercial purposes), subject to full attribution to the original publication and authors. The full terms of this license may be seen at: http://creativecommons.org/licences/by/4.0/legalcode

Vol. 8(4) 2019, Pg. 724 - 737

http://hrmars.com/index.php/pages/detail/IJARPED

JOURNAL HOMEPAGE

Full Terms \& Conditions of access and use can be found at http://hrmars.com/index.php/pages/detail/publication-ethics 


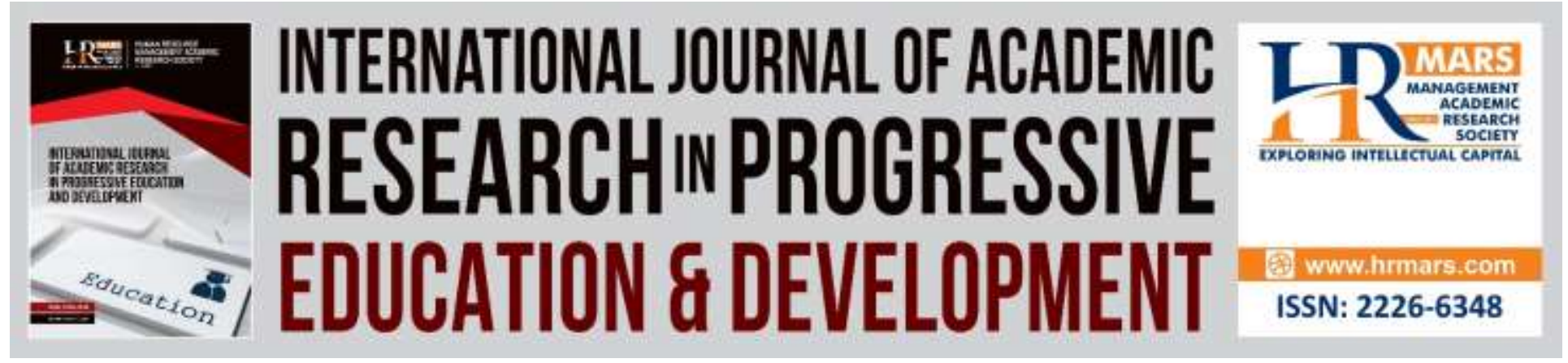

\title{
Augmented Reality in Teaching and Learning English Reading: Realities, Possibilities, and Limitations
}

\author{
Mohd Hafizuddin Mohamed Jamrus \\ Academy of Language Studies, Universiti Teknologi MARA (UiTM), Rembau Campus, Negeri \\ Sembilan, Malaysia \\ Email: mohamedhafizuddin@gmail.com
}

\begin{abstract}
Abu Bakar Razali
Faculty of Educational Studies, Universiti Putra Malaysia (UPM), Serdang, Selangor, Malaysia Email: abmr_bakar@upm.edu.my
\end{abstract}

\begin{abstract}
Mobile technology that has recently taken its flight into emergence is called Augmented Reality. Advancements of AR have largely incorporated its uses through mobile technology, which makes it possible for just about anyone who has a mobile device to use AR such as can be seen in the widespread popularity of the online mobile games. Although augmented reality is still in the beginning stages of making its way into the educational realm, it does offer the capabilities of greatly enhancing our educational system. In fact, based on previous scholarly studies, Augmented Reality has been shown to be effective in learning the English language and could improve student motivation. This conceptual paper thus reports on past studies on the use and usefulness of Augmented Reality in teaching and learning in English language reading. In this paper, the concept of Augmented Reality, its usage in language learning, the benefits of using AR in language learning, the limitations in using AR in language learning, and teacher's level of readiness and acceptance in using $A R$ in classroom reading instruction will be discussed. The authors will also provide some recommendations for stakeholders, especially in regards to the use of Augmented Reality in teaching of English language reading, and also suggestions for future research

Keywords: Augmented Reality, English Language Learning, Teacher's Acceptance, and Teacher's Readiness.
\end{abstract}

\section{Introduction}

Currently, mobile technology is the most widely used piece of technology in our world; almost everyone owns a mobile device e.g., smartphones, tablets, and can access the internet 
with ease, such as via Wi-Fi. Besides using mobile technology for day-to-day activities e.g., online transactions, instant messaging etc., there have been many developments in integrating mobile technology (as well as other technologies) in language and literacy education to see how it could be used effectively (Kukulska-Hulme, 2007). One of the more recent mobile technology used in the field of education is Augmented Reality, which was introduced in late 1960s, where it was initially used for visualization, training, and other purposes (Johnson, Levine, Smith, \& Stone, 2010).

Even though Augmented Reality is still in the beginning stages of making its way into the educational realm, it does offer the capabilities of greatly enhancing teaching and learning. Many institutions and researchers believe Augmented Reality could offer a lot in terms of its ability to enrich school curriculum across the nation (EDUCAUSE Learning Initiative, 2005). For instance, according to a research done by Chang, Morreale and Medicherla (2010), they claimed that using Augmented Reality could improve student motivation in language learning especially in English reading. Moreover, according to $\mathrm{Li}$, Guo, Zheng and Rau (2018), the implementation of Augmented Reality applications in the educational could promote reading and the teaching of reading skills.

Furthermore, according to Klopfer and Sheldon (2010), Augmented Reality can offer great potentials for the benefit of student learning by granting them to see an augmented world that they never experienced before due to geographical and cultural differences. In teaching English as a second language (ESL) reading, Augmented Reality can bridge ESL students' lack of background knowledge of the English language by augmenting students' surrounding and environment and fill it with digital information that can transform into an immersive and interactive learning experience a student's physical environment with digital information that can be modified into a compelling learning experience (Santos et al. 2016). As such, this conceptual paper reports on the review of literature of the findings of past research on Augmented Reality pertaining to teaching and learning of English reading, more particularly in term of its realities, possibilities and limitations. The authors also provide several suggestions in its use for the teaching and learning of English as a second language, and recommendations for future research.

\section{Reviewing the Literature: Augmented Reality in Teaching and Learning English Language Reading}

This literature review is divided into several sections. The first section is Augmented Reality technology, where the concept of Augmented Reality as a technology is discussed in details. In this section the authors also discuss the realities to the actual use and the application of Augmented Reality in language learning thus far. The second section reports on the possibilities and benefits of augmented reality in the teaching of English reading, to which this subheading will discuss the potential benefits of using augmented reality in the teaching of English reading in classroom. The third section discusses limitations of Augmented Reality in teaching and learning of English reading. The fourth section discusses English language teachers' acceptance and readiness in using technology/augmented reality in classroom. 


\section{Augmented Reality Technology and Its Use in English Language Learning (Realities)}

Kipper (2013) stated that Augmented Reality is a type of deviation from virtual reality. The technology of Virtual Reality immerses users under a synthetic environment and while being immersed in the technology, the user is unable to see the real world surrounding him. Augmented Reality takes computer-generated information or digital information such as sound, graphics and haptic awareness and superimposing them in a real environment. Kipper (2013), one of Augmented Reality's ability is that it can be utilized to improve all the human senses, however its commercial use is in the graphics and visual depiction. The differences between Augmented Reality and Virtual Reality is that the former allows the consumer of the technology to view the real world with the addition of the augmented and virtual objects depicted with the real world. Thus, Augmented Reality only acts as a reinforcer where it reinforces reality and not replace it with a completely new world.

There are various hardware technologies that take advantage of Augmented Reality for the purpose of displaying the virtual environment and other virtual elements over the user's realworld view. Head mounted displays (HMD) for instance, are a type of display where users wear on their head or as part of a helmet which has a small display optic in front of one or each eye. On the other hand, mobile handheld devices such as PDAs, tablets and smartphones, are small computing devices where users hold in their hands (Kesim \& Ozarslan, 2012). Nowadays, since almost everyone owns a smart phone, this type of device would be more widely used for Augmented Reality application as compared to HMDs. Augmented Reality apps on handheld devices can allow users to view augmented or overlaid digital information on their device's screen.

A number of studies have been conducted on using Augmented Reality in certain aspects of English language learning to see how AR can be used to facilitate learning. One aspect of English language learning that has been focused on is vocabulary learning. Solak and Cakir (2015) conducted a study to explore how materials designed with Augmented Reality would affect the vocabulary learning of undergraduate students who were at the beginner English language level due to the lack of suitable language learning materials that were catered towards the learners' level, which makes students found it difficult to learn new vocabulary. The AR material designed in the study aimed to recommend new language vocabulary words to students at the primary level which incorporated animation and sound in order to make the material more interesting for the learners. The results showed that students were motivated towards vocabulary learning, which also positively correlated with their academic achievement.

In another study by Liu (2009), Augmented Reality application was used in the construction of an English learning environment known as the Handheld English Language Learning Organization (HELLO) where sensors and ubiquitous computing was integrated to facilitate language listening and speaking among 7th grade students. Learning games were designed which included topics that were related to different areas (or zones) in the school such as the laboratory and stationery store among other areas. This was an outdoor activity where students could move around freely to any of the areas and learn/practice/engage in conversations with a Virtual Learning Tutor $(V L T)$ that were related to the particular area on their PDA device. The results from this study showed that students had less anxiety in practicing speaking as they were unafraid to speak to the software i.e., the VLT as compared to a real 
person. Thus, the students could achieve better learning as they also felt satisfied and enjoyed the activity.

Tobar-Munoz, Baldiris and Fabregat (2017) also conducted a study focusing on the aspect of reading comprehension where Augmented Reality game-based learning was incorporated to create a sort of an augmented 3D book to enrich students' learning experience. As many as 51 third through sixth graders participated in the activity in pairs using a Tablet which involved answering reading comprehension questions after going through different scenes in a book where the AR application superimposed virtual imagery to illustrate certain aspects of the book. From this study, the students were found to have more enjoyment as compared to solely reading from a book. An interesting thing to note was that for more "opinion" based comprehension questions, students gave more informed, stronger, and longer answers as compared to the controlled group which only read the book without the use of Augmented Reality.

It is important to note regardless of the research reported above, unfortunately there is relatively few studies done on Augmented Reality use in English language teaching and learning. The studies described above are a few prominent ones which have explored Augmented Reality in different aspects of language learning.

\section{Benefits of Using Augmented Reality in the Teaching of English Reading (Possibilities)}

Augmented Reality provides a difference in education, where it offers a change from the conventional style to a more interactive one which allows students to interact with the learning content (Kucuk, Yilmaz \& Goktas, 2014). Augmented Reality offers simulations where operations of real-world processes are imitated. When students interact with the learning tool, they actively participate in these simulations, which give them some control over what they are learning (Ramya \& Madhumathi, 2017). With that, the interactive nature of Augmented Reality induces student participation towards a goal, making the teaching style student-centric. This is beneficial to the teaching of reading because when students can see the image of what they are reading about, it is easier for them to understand the text and makes the teaching of reading much easier. This technology provides students with virtual images that can supplement the lack of background knowledge that students, especially ESL students have when reading English text (Yang, 2011).

Besides being interactive, Augmented Reality is also immersive in nature in a sense that students experience authentic physical and mental situations similar in the real world, through their interaction with the virtual environment (Liu, 2009). Liu's study showcased the immersive nature of Augmented Reality where a context-aware immersive activity was designed which was able to improve the learning experience which in turn increased students' results. According to Whiteside (2002), in order for an environment to be immersive, it has to engage the learner cognitively, emotionally, and physically by incorporation of real-world stories/tasks, inclusion of learner-required resources within the environment, provision of as much authenticity as possible, and utilization of real-time synchronous events. Augmented Reality manages to provide such an immersive environment through its technologies and design. Having an immersive environment will help students in visualizing visual imageries presented in a fiction (Wong \& Looi, 2010). Teachers can take this advantage and use it in their teaching of English reading, which is helpful when giving students fictional titles for them to read either for leisure or for academic 
purposes. This is beneficial in teaching reading because students usually lack the motivation to read because they think it is a dull and boring activity. According to Brown (2007), students' motivation for reading usually stems from high intrinsic motivation. Having an immersive environment to read compared with the traditional black and white text will increase students' intrinsic motivation in reading which will be beneficial for teachers and students in the teaching and learning of English reading in the classroom.

Another nature of Augmented Reality which helps in engaging students is in terms of practicality, where the learning content can be made more relevant to learners. According to Keller's (1987) ARCS model, relating new information to information which the students are familiar with helps make the learning material relevant and subsequently increases student motivation towards learning. In this vein, the researcher believes that Augmented Reality can make the learning material practical for the student. For instance, real objects can be annotated with audio, text, graphics, and animations registered onto the environment in 3D, helping students visualise information through explicit illustration of the relationships of these virtual elements with those found in the current environment e.g., linking vocabulary (virtual elements which pop up on the screen) with real world objects (Santos et al., 2016). Thus, students are able to come up with authentic connections between the learning material and the real world through visualising information in a context-rich environment (Santos et al., 2016). According to Wu et. Al (2013), students can improve rapidly in their reading comprehension using Augmented Reality as such when they encounter unfamiliar words and can use the interactive interface to figure out the meaning of the unfamiliar word. This can also reduce the burden of teacher having to go to each student for clarification in reading.

Since Augmented Reality has the nature of being interactive, immersive, and practical, it manages to engage students towards the learning environment by enriching input, encouraging participation, and helping learners connect content with real life contexts. When students begin to engage in Augmented Reality applications, the engagement further facilitates positive affective factors. For instance, Augmented Reality applications increase motivation of students in learning a certain topic as compared to conventional methods (Kucuk, Yilmaz \& Goktas, 2014). In addition, students have less anxiety and an increased enthusiasm, eagerness, and excitement to take part in activities that integrate Augmented Reality in the lesson (Silva, Roberto \& Teichrieb, 2015). Other positive affective factors that have resulted from Augmented Reality use in language learning are increase in confidence due to students themselves having more control over their learning, increase and retention of attention towards the lesson due to their excitement in using the Augmented Reality enabled device (Mahadzir \& Phung, 2013), and increase in self-confidence towards learning (Solak \& Cakir, 2015). With that, Augmented Reality applications can indeed be used as a tool to promote engagement in various ways for students in their language learning. When students are confident and motivated in reading, it will help teachers in that teachers will have more options in conducting their reading lessons because the students are ready to learn due to their increased confidence in reading. According to Brown (2007), students' confidence and high self-esteem can be infectious to other students which will lead to a productive classroom where all the students are eager to learn reading. This will create a positive ecosystem for both the teacher and the students to teach and learn reading in the classroom. 
Bacca (2014) found that students who used Augmented Reality applications in an English reading class tend to exert less effort in the process of implementation AR in the classroom. It is also proven in this study that students' attitude towards Augmented Reality was positive and they showed a high degree of achievement in the English reading skills after using the AR application. Also, students who experienced $A R$ in the classroom have a positive mindset in which they are excited to use the AR technology in learning English reading skills in the future. Furthermore, they showed a sense of satisfaction with the implementation of AR and portrayed low amount of anxiety while using AR in the classroom. Augmented Applications have attracted students' attention and have offered a new, effective and interactive learning environment and also increase their motivation in learning the English language. This series of results may be due to the fact that students have shifted from a traditional classroom into a more modern and interactive learning environment in learning the content of the English language.

Bacca (2014) also found there is a positive but low correlation between attitude and achievement. The correlation means that for students who possess good behavior towards Augmented Reality applications have more success in their study than the students who have negative attitude towards Augmented Reality in their learning. The author's observation of the data is, the levels of cognitive burden between successful and not successful students are adjacent to each other. The author claimed that this observation is the explanation behind the findings mentioned previously. Interestingly, in other works of literatures such as Bradford (2011), Salomon (1983) and Tuckman (2003), there is a contrast in findings where usually the level of cognitive load will have significant relationship with students' level of satisfaction in their learning situation and their achievement.

In another research by Vate-U-Lan, P. (2012), he mentioned that students show an increase in their level of motivation when learning English reading skills through AR and they enjoy and have a positive attitude towards the implementation of AR in learning the English language as a whole. There is a study which compared the results of students' achievement in the traditional classroom and an AR classroom setting. It is found that students who worked with Augmented Reality had increased their listening, speaking and reading skills in comparison with students in the conventional classroom setting (Barreira, 2012). It comes back to the root and purpose of learning English in the classroom. Students' competence in the language is one of the most important goals for teachers to achieve in an English classroom. It has been proven in several studies that using Augmented Reality can not only improve students' achievement on paper, but also increase their affective domain such as motivation and decrease their anxiety level when using the technology.

In another study by Yilmaz (2014), the researcher measured and analyze students' attitudes towards the implementation of technology and their level of cognitive loads. They found out that students with higher performance were more positive towards the implementation of technology. Another finding was there is no difference in mean between attitude and levels of cognitive load. Based on the mean recorded from the samples, it was observed that both successful and unsuccessful group of students possess high mean score which means they possess good attitude towards technology use. High mean score of high performing students could indicate that their engagement level with the subject was increased by the technology which leads to the increase in engagement time which results to increase in positivity 
in attitudes. The conclusion of this study is, the implementation of technology may have affected the increase in students' level of achievement in education.

Researchers have studied on Augmented Reality in education have stressed on the several positive challenges that Augmented Reality games can provide for teachers and students. Dunleavy (2009) claimed that Augmented Reality can augment and create a safe learning environment for students that can enhance and improve their skills (i.e., cooperation, social interaction, collaboration and teamwork). This provides the similar outcomes as the jigsaw pedagogy where high level of engagement between the students and the content is the salient feature. The researcher claimed that the collaborative skills that students achieve from this will be importance to support their learning and can help them to memorize into their long-term memory of the knowledge and information provided by engaging lessons.

One of the reasons why Augmented Reality captured the interest of researchers in the education field is its ability to virtually augment data and information which could be combined with external information in order to present new interactive and fun learning experience especially in English language learning. Augmented Reality applications are able to attract students' attention and create an effective learning environment due to a few reasons (Fabregat, Baldiris \& Munoz, 2017). In addition, AR is also known to increase student engagement, which refers to how invested and involved a student is in learning a particular subject, which would include both eagerness in learning and active task participation. Student engagement also deals with the interest, attitude, motivation, attention and curiosity that the student displays towards learning. Fredricks, Blumenfeld and Paris (2004) identify the dimensions that make up student engagement which are: (1) behavioral (willingness to participate and actions taken), emotional (affective reactions), and cognitive (investment in learning) engagement. Many studies have defined these dimensions to include a broader sense of engagement to not merely the learning of a subject and task participation, but also towards the learning institution environment itself e.g. adherence to school rules, classroom attendance, attitudes towards teachers and classmates, extracurricular activities (Axelson \& Flick, 2010; Trowler, 2010).

\section{Issues with Augmented Reality (AR) In Teaching and Learning of English Reading (Limitations)}

From the review of literature, there are several issues or limitations of Augmented Reality (AR) in the learning of the English language. The first limitation is that it was found students, when using $A R$ in the teaching and learning session, might difficulties and problems in maintaining superimposed information. According to a study done by Bacca et al. (2014), some students had to deal with frustration when the AR application does not properly work as intended or another case scenario in which it is rather burdensome for the students to utilize the device or markers to gain access to the augmented information. Bacca et al. (2014) believe that the potential solution for this limitation is application developers need to improve the algorithms in the tracking and the processing of image department. Furthermore, one of the recommendations regarding this limitation is for future researchers to explore the realm of AR and study its usability in the field of education along with the establishment of the guidelines for the model of Augmented Reality in the educational contexts

The second limitation is the distraction that AR might provide from learning and that the students would pay more attention to the virtual and augmented information rather than the 
real education content present in the AR application. In relation to the second limitation mentioned, it is closely associated with the fact that AR is novel to the students and thus students may experience distraction when using the technology. The students may get distracted by the Augmented Reality technology and the augmented and virtual information (Kesim \& Ozarslan 2012).

The third limitation is that Augmented Reality can be considered as an "Intrusive Technology." Augmented Reality can be a source of intrusion for students learning of the reading skills when they use the equipment such as the head-mounted displays (HDM) in the teaching and learning session. Zarraonandia, Aedo, Diaz and Montero (2013) mentioned in their studies that the device used to convey virtual information can disrupt the natural engagement between students with other students and students and teachers' interaction. Another form of intrusiveness is the fact that in order to fully utilize this technology in the classroom, a class need to be fully equipped in the hardware department and stable internet connections.

\section{English Language Teachers' Acceptance and Readiness in Using Technology/Augmented Reality in Classroom}

Despite the usage of Augmented Reality in the field of education gradually increasing over time, especially with the rapid growth of the mobile devices industry, the level of acceptance of Augmented Reality in educational context is still relatively low. In order to enhance and improve the quality of technology and its usage in the near future, it is important for researchers to gauge the consumers' level of acceptance (Dalim, Kolivand, Kadhim, Sunar \& Billinghurst, 2017). Teacher's acceptance and readiness towards the implementation of technology in their classroom instruction is crucial because if they have negative acceptance on the usage of technology, it will be difficult for the implementation of said technology. On the other hand, if they have too positive perceptions on this implementation, it will lead to negative consequences as well. According to Yoon et al. (2012), one thing that can happen if teachers are too positive about the implementation of Augmented Reality in the teaching of English reading is that the lesson might be carried away by the technology. Thus, teacher's assessment and feedback are always an important factor in the classroom setting and by focusing way too much on the technology will lead to an artificial classroom that is not meaningful for the students (Alderson and Banarjee, 2001).

Several research has been done by scholars who were keen in the potential that Augmented Reality has for the future and they have reported the fundamental elements which may influence the level of acceptance among teachers. According to Dillon (2001), there are six key factors that will influence teacher's acceptance in using AR in the classroom. The first key factor is curriculum, where the technical condition of Augmented Reality has to be balanced with the current pedagogy beliefs of the country. Second, the interaction between Augmented Reality with its users need to be very stable in order to be reliable in providing uninterrupted session during the learning process. Third, the capability to provide the element of autonomy in learning where the interaction with Augmented Reality does not need elaborate guidance from teachers and parents. Fourth, involvement of important people for the students such as parents is also important to increase the level of acceptance of Augmented Reality in teaching English reading, where the participation and support from parents can contribute to positive acceptance of AR. 
Fifth, students' social economic background is an important consideration. Lastly, the platform used to implement Augmented Reality needs to be solid as it is the physical requirement in the form of devices that are integral in the launching of Augmented Reality applications in classroom. These key factors are important to ensure teachers' acceptance in using Augmented Reality in the teaching of English reading.

In a research done by Aziz, Nor and Nikian (2013), they researched on the perceptions of Malaysian secondary school teachers in the application of technology use in the Malaysian classroom. They conducted a qualitative study and found out that most of the participants use technological devices in an everyday basis. They use the internet frequently and they claim that they have basic knowledge for using technology in their lives. Participants in this study show that they have ample knowledge in using technology for the purpose of teaching and learning session. The result of the study showed that teachers have positive perceptions and they have high level of familiarity in the usage of technology and they reported to have no problems with the implementation of technology for their classroom instruction. The researchers reported that the difficult part in using technology in a classroom is the lack of computers, lack of time in the preparation of lesson plans involving technology and little to no technical support provided in schools. Despite these difficulties, teachers in this study reported to have great motivation in going for in service training if it means that they can improve their technological knowledge and skills for the benefits of their students.

In a study done by Singh and Chan (2014), it was found that the knowledge on how to use technologies, such as Augmented Reality, in the learning and teaching environment has a prominent effect in order to effectively implement them in the classroom. Another important factor that needs consideration is the teacher's perception and readiness towards using them. According to the study, teachers who had lesser teaching experience had higher levels of technological knowledge as well as better attitudes. The study also reported that when there is an increase in ICT experience, their attitudes also showed improvements which led to the conclusion that continuous teacher training played a vital role in this study.

Singh and Chan (2014) also revealed that teachers' level of knowledge on technology is mediocre and they are good at selected software usage such as emails, presentation software (PowerPoint), spreadsheet software (Excel) and word processing software (Word) because these are main software that they use when they are working. Next, according to the study, the teachers demonstrated mixed level of readiness. This result is in compliance with research carried out by Lau and Yeoh (2008), Melor (2007) and Samuel and Zaitun (2007). This study showcased that according to the demographic data, teachers who are aged 45 and above are not ready to implement Augmented Reality in their teaching, but are ready if they only have to use basic software such as Microsoft Word and PowerPoint. Whereas, for teachers aged 45 and below are ready to implement Augmented Reality in their teaching and they are ready if needed extra training for the implementation.

On another note, a study done in Simunjan District in Sarawak by Hussein and Kaur (2015) to assess the extent which secondary teachers are ready and prepared in order to implement electronic technology in their classroom instruction; the researchers found that most secondary schools are equipped with Internet accessibility however the service is not satisfactory and teachers in the district lack the technological skills in using technology/ICT in their classroom 
instruction. This implies that teachers in this district are not ready to use or implement technology for educational purposes in their teaching learning session. In this regard, much like the results of this particular study, the issue of lack of facilities in order to facilitate the implementation of technology and Augmented Reality in the classroom should also be addressed.

\section{Conclusion}

As a conclusion, it was elaborated in this conceptual paper on the technology of augmented reality and how it could benefit the education sector primarily on the learning of the English language. Despite all the limitations mentioned above, there are more benefits to Augmented Reality especially in teaching reading. The researcher believes that these challenges should not impede the implementation of Augmented Reality in the teaching of English reading. This is due to the fact that the problems for the hardware components such as glitches and bugs will be solved by manufacturers and companies in the future. If schools can meet the requirements and challenges in implementing Augmented Reality applications in the classroom, it will provide its benefits and usefulness in our education system (Akcayir \& Akcayir 2016). The expectation of rapid technology advancement and development, Augmented Reality will be improved in the future which will lead to a more dispersed distribution in terms of its use especially in the education field. Therefore, investing in Augmented Reality by researching on it is important if we want to take full advantage of its ability to enhance our education quality especially in terms of English reading.

The technology of Augmented Reality is still relatively new and not a lot of research have been done on its impact on language learning. Augmented Reality is a technology rapidly rising and it will be a waste to if we do not take the opportunity to use this technological advancement to improve our education sector especially in learning English. There are still many things to take into consideration before we can implement this in real environment of classroom instruction. Factors such as teacher's level of readiness, acceptance, knowledge, cultural values need to be investigated further before proceeding to the actual implementation of this conceptual paper. In order to successfully implement Augmented Reality or technology in the classroom, English language teachers need to have positive mindset and attitudes (perception and readiness) in accepting technology and those who see it as useful in promoting learning will have an easier time integrating ICT or Augmented Reality in their classroom.

It is important not only for the teachers to be ready, knowledgeable and have a positive mindset towards the implementation of technology in the classroom but also the fact schools need to be well-equipped with the devices needed for the implementation of technology in the classroom before we can implement in in real classroom situation. It is important to consider all these aspects such as teacher's readiness, perception and acceptance of using Augmented reality in the teaching of English reading skills and school's infrastructure and internet access before implementing it for real in the classroom. When implementing a new policy or technology into the classroom, the one conducting the lesson is the teachers. It is very important that we put teachers first before implementing Augmented Reality in classroom to find out whether they will agree or not agree with the implementation. If teachers are not happy with the implementation, it will never be successful, because in the end, teachers are the one who will conduct a lesson. 
INTERNATIONAL JOURNAL OF ACADEMIC RESEARCH IN PROGRESSIVE EDUCATION AND

DEVELOPMENT

Vol. 8, No. 4, 2019, E-ISSN: 2226-6348 @ 2019 HRMARS

\section{Acknowledgement}

This research was made possible due to research grant in the scheme of Geran Putra (or Putra Grant) by Research Management Centre, Universiti Putra Malaysia (UPM).

\section{Corresponding Author}

Abu Bakar Razali (PhD), Faculty of Educational Studies, Universiti Putra Malaysia (UPM), Serdang, Selangor, Malaysia

Email: abmr_bakar@upm.edu.my

\section{References}

Akcayır, M., Akcayır, G., Pektaş, H. M., \& Ocak, M. A. (2016). Augmented reality in science laboratories: The effects of augmented reality on university students' laboratory skills and attitudes toward science laboratories. Computers in Human Behavior, 57, 334342.

Alderson, J. C., \& Banerjee, J. (2001). Language testing and assessment.

Axelson, R. D., \& Flick, A. (2010). Defining student engagement. Change: The magazine of higher learning, 43(1), 38-43.

Aziz, A. M., Nor, M. F., Nikian, S. (2013). Malaysian Teachers' Perception of Applying Technology in the Classroom.

Bacca, J. (2014). Augmented Reality Trends in Education: A Systematic Review of Research and Applications.

Barreira, J. (2012). Augmented Reality game to learn words in different languages: Case study: Learning English names of animals in elementary school.

Brown, H. D. (2007). Principles of Language Learning and Teaching. (5 $5^{\text {th }}$ ed.). New York: Pearson Education.

Dalim, C. S. C., Kolivand, H., Kadhim, H., Sunar, M. S., Billinghurst, M. (2017). Factors Influencing the Acceptance of Augmented Reality in Education: A Review of the Literature.

Davis, F., D. (1980). A technology acceptance model for empirically testing new end-user information systems: theory and results.

Dillon, A. (2001). User acceptance of information technology. In W. Karwowski (Ed), Encyclopedia of human factors and ergonomics. London: Taylor and Francis.

Dunleavy, M., \& Dede, C. (2009). Augmented reality teaching and learning. In Handbook of research on educational communications and technology (pp. 735-745). Springer, New York, NY.

Fabregat, R., Munoz, H. T., Baldiris, S. (2017). Augmented Reality Game-Based Learning: Enriching Students' Experience During Reading Comprehension Activities

Fredricks, J. A., Blumenfeld, P. C., Paris, A. H. (2004). School Engagement: Potential of the concept, state of the evidence.

Kipper. (2013). Augmented Reality: An Emerging Technologies Guide to AR. Syngress.

Keller, J. M. (1987). Development and use of the ARCS model of instructional design. Journal of instructional development, 10(3), 2. 
Kesim, M., \& Ozarslan, Y. (2012). Augmented reality in education: current technologies and the potential for education. Procedia-Social and Behavioral Sciences, 47, 297-302.

Kucuk, S., Yilmaz, R., \& Goktas, Y. (2014). Augmented reality for learning English: achievement, attitude and cognitive load levels of students. Egitim ve Bilim, 39(176).

Kaur, T., \& Hussein, N. (2014). Teachers' readiness to utilize Frog VLE: A case study of a Malaysian secondary school. Journal of Education, Society \& Behavioral Science, $\quad 5(1), 20-29$.

Lau, T. C., and Yeoh, K. H. (2008). Learning behaviour of university's business students in regards to gender and levels of study-an exploratory research. Proceedings of

International Conference of Social Sciences and Humanities. Penang: Universiti Sains Malaysia.

Liu, P. E., \& Tsai, M. (2013). Using augmented-reality-based mobile learning material in EFL English composition: An exploratory case study. British Journal of Educational Technology, 44(1), E1-E4.

Liu, T. Y. (2009). A context-aware ubiquitous learning environment for language listening and speaking. Journal of Computer Assisted Learning, 25(6), 515-527.

Long, M. (1985). Input and second language acquisition theory.

Mahadzir, N. N., \& Phung, L. F. (2013). The use of augmented reality pop-up book to increase motivation in English language learning for national primary school. Journal of Research \& Method in Education, 1(1), 26-38.

Ramya, G., \& Madhumathi, P. (2017). Adopting Augmented Reality for English Language Teaching and Learning. Language in India, 17(7).

Samuel, R., and A. Zaitun, 2007. Do teachers have adequate ICT resources and the right ICT skills in intergrating ICT tools in the teaching and learning of english language in Malaysia schools? The Electronic Journal of Information Systems in Developing Countries, 29(2): 1-15.

Santos, M. E. C., Taketomi, T., Yamamoto, G., Rodrigo, M. M. T., Sandor, C., \& Kato, H. (2016). Augmented reality as multimedia: the case for situated vocabulary learning. Research and Practice in Technology Enhanced Learning, 11(1), 4.

Scherer R., Tondeur, J. Siddiq, F., Baran, E. (2018). The importance of attitudes toward technology for pre-service teachers' technological, pedagogical, and content knowledge comparing structural equation modeling approaches.

Silva, M. M. O., Roberto, R., \& Teichrieb, V. (2015). Evaluation of augmented reality technology in the english language field. In Brazilian Symposium on Computers in Education (Simpósio Brasileiro de Informática na Educacão-SBIE) (Vol. 26, No. 1, p. 577).

Singh, T. K. R., Chan, S. (2014). Teacher Readiness n ICT Integration in Teaching-Learning: A Malaysian Case Study.

Solak, E., \& Cakir, R. (2015). Exploring the Effect of Materials Designed with Augmented Reality on Language Learners' Vocabulary Learning. Journal of Educators Online, 12(2), 50-72.

Tobar-Munoz, H., Baldiris, S., \& Fabregat, R. (2017). Augmented Reality Game-Based Learning: Enriching Students' Experience During Reading Comprehension Activities. Journal of Educational Computing Research, 55(7), 901-936.

Trowler, V. (2010). Student engagement literature review. The higher education academy, 11, $1-15$. 
Vate-U-Lan, P. (2012). An Augmented Reality 3D Pop-Up Book: The Development of a Multimedia Project for English Language Teaching.

Whiteside, A. J. (2002). Beyond interactivity: Immersive web-based learning experiences. The e-Learning Developers' Journal, 283, 1-10.

Wong, L. H., Looi, C. K. (2011). What seams do we remove in mobile-assisted seamless learning? A critical review of the literature.

Yang, Y. F. (2011). Engaging students in an online situated language learning environment, Computer Assisted Language Learning, 24(2), 181-198.

Yilmaz, R. (2014). Augmented Reality for Learning English: Achievement, Attitude and Cognitive Load Levels of Students.

Yoon, S. A., Elinich, K., Wang, J. (2012). Using augmented reality and knowledge-building scaffolds to improve learning in a science museum.

Zarraonandia, T., Aedo, I., Díaz, P., \& Montero, A. (2013). An augmented lecture feedback system to support learner and teacher communication. British Journal of Educational Technology, 44(4), 616-628.

Al-oshaibat, S. D. (2018). The Impact of the Binomial Option Pricing Model on Designing Hedge Portfolio. Empirical Study on Banking Sector in Amman Stock Exchange, International Journal of Academic Research in Accounting, Finance and Management Sciences 8 (2): 272-280. 